\title{
Perfumeen kimika: \\ musketak eta musketa poliziklikoen analisia
}

Josu Lopez-Gazpio*, Esmeralda Millán

Kimika Aplikatua Saila. Kimika Zientzien Fakultatea (UPV/EHU)

*josu.lopez@ehu.eus

DOI: $10.1387 /$ ekaia.14129

Jasoa: 2015-03-15

Onartua: 2015-06-18

Laburpena: Kromatografia elektrozinetiko mizelar ezurtsuan oinarrituta metodo bat garatu da perfumeetan Galaxolide ${ }^{\circledR}$, Tonalide ${ }^{\circledR}$ eta Traseolide ${ }^{\circledR}$ musketa poliziklikoak kuantifikatzeko. Konposatu horiek kosmetikoen osagai moduan asko erabiltzen dira zainketa pertsonalerako produktuetan. Metodoa optimizatzeko esperimentu-diseinua eta erantzun-gainazalen metodologia erabili ziren. Metodoaren ezaugarri analitikoak ebaluatu ziren eta balio onargarriak lortu ziren ezaugarri hauei dagokienez: linealtasuna, detekzio- eta kuantifikazio-mugak, doitasuna eta zehaztasuna. Optimizatutako eta balioztatutako metodoa perfume-lagin komertzialetan hautatutako osagaiak determinatzeko erabili zen.

Hitz gakoak: Elektroforesi kapilarra, Kromatografia elektrozinetiko mizelarra, Musketa poliziklikoa, Perfumea.

\begin{abstract}
A nonaqueous micellar electrokinetic chromatography method was developed for quantification of Galaxolide ${ }^{\circledR}$, Tonalide ${ }^{\circledR}$ and Traseolide ${ }^{\circledR}$ polycyclic musks in perfumes. These compounds are widely used as cosmetic ingredients in personal care products. The method was optimized by using experimental design and response surface methodology. The analytical characteristics of the method were evaluated, providing acceptable values in terms of linearity, limits of detection and quantification, precision and accuracy. The optimized and validated method was applied for determination of the selected ingredients in commercial perfume samples.
\end{abstract}

Keywords: Capillary electrophoresis, Micellar electrokinetic chromatography, Perfume, Polycyclic musk.

\section{SARRERA}

Usainek oharkabean alda edo bideratu dezakete gure portaera. Dastamena eta usaimena dira bizidunon informazio iturri zaharrena, inguratzen gaituenari buruzko datu kimikoak eskuratzeko bidea [1]. Usainak bereziki 
garrantzitsuak dira giza portaeretan, eta horiei eragitea horietan eragitea izan da, hain zuzen ere, perfumeen xede nagusietakoa. Perfumeen historiaren hasierak bat egiten du gizateriaren historiarekin. Historiaurrean lehen gizakiak hainbat materialen usain onaz konturatu zirenetik, perfumeak mendeetan zehar erabili izan dituzte faraoi, enperadore, konkistatzaile eta monarka askok, euren gortesau eta alkimistekin batera. Horrek perfumeen zientzia eta teknologiaren aurrerapen izugarria ekarri zuen, eta ondoren, garapen horiek guztiak beste esparru ugaritan erabili ahal izan ziren [2].

Historiaurrean usainek garrantzi jainkotiarra zuten erlijioan. Geroago, Grezian eta Erroman ere oso preziatuak izan ziren espezia, olio eta perfumeak: arrakasta edota gizarte maila altua erakusteko ikur gisa erabiltzen zituzten intsentsua, mirra, azafraia, kanela, arrosa-esentzia eta abar. Erromako inperioak iraun zuen bitartean, produktu horien merkataritza oparoa izan zen Ekialde Urrunetik Mediterraneora. Erdi Aroan, alkimista arabiarrek esentziak distilatzeko alanbikea asmatu zuten, eta euren eskutik iritsi ziren perfumeen lehen errezeta-liburuak [3]. Hurrengo mendeetan ere izan ziren perfumeekin harremana zuten gertaerak. Horien artean aipatzekoa da Florentzia, Venezia, Genoa eta horrelako merkataritza-hirietan perfumeek izandako garrantzia. Bestetik, Amerika aurkitzea ekarri zuen Kristobal Kolonen bidaien arrazoi nagusienetakoa: Ekialde Urrunean zeuden produktu exotikoen merkataritza areagotzeko nahia.

XVIII. mendean, kimika modernoa lehen pausoak ematen hasi zen, eta garai hartako lurringintzaren munduan bi gertakizun ditugu aipagarri. Alde batetik, 1708an, Charles Lilly lurringileak lehen aldiz animalia jatorriko konposatu bat erabili zuen merkaturako perfume baten konposizioan: musketa [4]. Bestetik, 1710ean Giovanni Maria Farinak gaur egun ere ezaguna den Eau de Cologne perfumea sortu zuen (1. irudia). Kimikaren ikuspuntutik, 1882an aurrerapauso handia eman zen: Paul Parquet lurringile frantsesak erabili zuen lehen aldiz laborategian sintetizatutako konposatu bat, Fougere Royale perfumearen osagai bezala. Konposatu hori kumarina zen - zenbait landarek duten osagai usaintsua-, William Perkin kimikariak 1868an sintetizatu zuen molekula, hain zuzen ere [2].

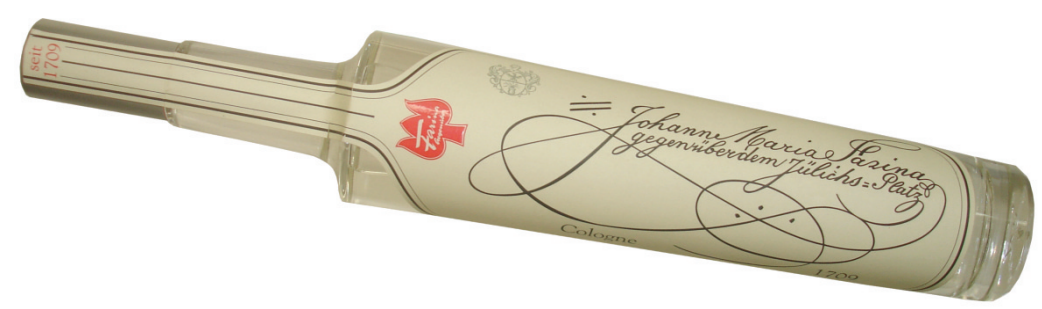

1. irudia. Eau de Cologne perfumeak arrakasta handia izan zuen XVIII. mendean. Arg.: Wikimedia Commons, jabego publikoan. 
Perfumeen kimika: musketak eta musketa poliziklikoen analisia

XX. mendean zehar, eta gaur egunera arte, perfumeen erabilera izugarri zabaldu da, eta azkenean gizarte-maila guztietara iritsi da. Era berean, usain gozoen eta perfumeen kimikak aurrerapauso ikusgarriak eman ditu hainbat esparrutan. Analisi teknika berriei esker eta sintesi-kimika organikoari esker, beste konposatu batzuk bilatu, identifikatu eta sintetizatu ahal izan dira. Industria kosmetikoaren sofistikazioa maila gorenetara iritsi da, eta 3.000 osagai usaintsu - hau da, lurrin - baino gehiago daude eskuragarri [4], besteak beste, musketak.

\section{MUSKETA-MOTAK}

Musketa naturala Moschus moschiferus orein musketadun espeziearen arraren guruin usain-sortzaileen jariakinetik lortzen da, eta mendeetan zehar usain gozo bezala erabili da (2. irudia). Hain zuzen ere, oreinaren jariakinean \%0,5-2 arteko proportzioan dagoen konposatu kimiko batek sortzen du musketa usaina. Molekula hori muskona da: 15 atomoko zikloa eta $\mathrm{C}_{16} \mathrm{H}_{30} \mathrm{O}$ formula molekularra duen zetona makroziklikoa -3-metil-1-ziklopentadekanona, hain zuzen ere- . Musketa produktu naural garestienetako bat da, 30.000-50.000 \$/kg-ko prezioa baitu. Horretaz gain, 40 orein hil behar dira. Hori guztia dela eta, laster gertatu ziren kalte ekologikoak. Orein musketaduna desagertzeko zorian egon zen eta egun babestuta badago ere, arriskuan dago, batez ere legez kanpoko ehizaren ondorioz. Egun, kimikak sintesi bidez eskaintzen dituen aukerak erabiltzen dira lurringintzan.

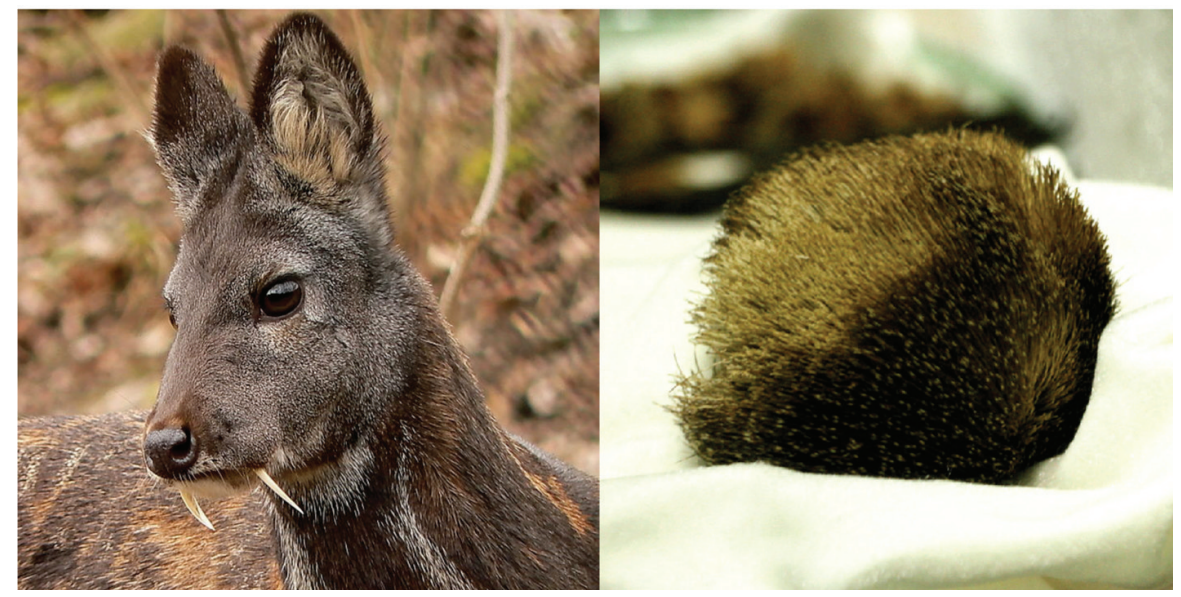

2. irudia. Orein musketaduna, Moschus moschiferus (ezkerrean) eta erauzitako guruina (eskuinean). Arg.: Wikimedia Commons, CC-BY-SA. 
Musketa usaina duen lehen molekula sintetikoa, Musk Baur delakoa, 1888an Albert Baur kimikariak lortu zuen [5]. Aurkikuntza guztiz zorizkoa izan zen, haren helburua TNT baino egonkorragoak izango ziren lehergaiak lortzea baitzen. Musketa naturala oso garestia delako, eta konposatu hori era arrakastatsuan merkaturatu zen. Beraz, Baurrek aurrera egin zuzen ikerketetan, eta beste hiru nitromusketa aromatiko sintetizatu zituen: zetona musketa (MK, musk ketone), xileno musketa (MX, musk xylene) eta abelmosko musketa (MA, musk ambrette). Geroago beste bi nitromusketa gehiago sintetizatu ziren - musk moskene (MM) eta musk tibetene (MT) - , eta aipatutako azken bost nitromusketa horiek arrakasta handia izan zuten lurringintzan eta kosmetikan, 1990eko hamarkada bukatu arte. Izan ere, urte horietan agerian utzi ziren nitromusketen neurotoxikotasuna, fototoxikotasuna eta ingurumenari egindako kaltea. Ondorioz, nitromusketak gutxiago erabili zituzten, eta zenbait kasutan, legediak debekatu egin zituen. Europar Batasunaren kasuan, MA, MT eta MM debekatuta daude eta MXren zein MKren erabilpena mugatuta dago [6].

Musketa poliziklikoak Xx. mende erdialdetik ezagutzen ziren, eta pixkanaka nitromusketak ordezkatzen joan ziren; egun haiek dira musketa sintetiko erabilienak. Musketa poliziklikoak (PCM) bi edo hiru zikloz osatuta daude eta usain bereziki erakargarria dute. Horretaz gainera, gai dira perfumeen konposizioan dauden beste osagaien usainak finkatzeko, eta, hartara, perfumearen usainak gehiago irauten du. Merkatuaren ikuspuntutik, Galaxolidea ${ }^{\circledR}$ (HHCB) eta Tonalidea ${ }^{\circledR}$ (AHTN) dira musketa polizikliko garrantzitsuenak (1. taula). Mota guztietako etxeko produktuetan erabiltzen dira, adibidez perfumeetan, kosmetikoetan, xaboietan, xanpuetan, detergenteetan eta garbiketarako bestelako produktuetan. Horiez gain, badira beste zenbait musketa polizikliko ezagun: Phantolidea ${ }^{\circledR}$ (AHDI), Traseolidea ${ }^{\circledR}$ (ATII) eta Celestolidea $^{\circledR}$ (AHMI), besteak beste [7]. Azken urteotan ikusi da PCMak toxikoak izan daitezkeela - erresistentzia multixenobiotikoaren inhibitzaileak dira, esate baterako [8] - eta ingurumenean nahiz bizidunetan metatzeko gaitasuna dute [9]; beraz, sakonago aztertu behar da zer-nolako albo ondorio eta kalte sor ditzaketen.

Azken hamarkadan, musketa makrozikliko sintetikoak garrantzia hartzen ari dira. Laborategian sintetizatutako molekulak dira, baina naturan dauden musketen egitura kimikoak imitatuz lortzen dira - aurrez aipatu den muskona naturala imitatuz, besteak beste - . Badira azken belaunaldiko beste zenbait musketa makrozikliko ere (Muscenone, Exaltolide ${ }^{\circledR}$, Nirvanolide ${ }^{\circledR}$, eta abar), lurrintzan geroz eta erabiliagoak direnak. Orain arte dakigunari jarraiki behintzat, badirudi musketa makroziklikoen biodegradagarritasun arazoak poliziklikoenak baino arinagoak direla [10]. 
1. taula. Musketa poliziklikoak (PCM).

\begin{tabular}{cccc}
\hline Izen arrunta & CAS zenbakia & Laburdura \\
Galaxolidea $^{\circledR}$ & $1222-05-5$ & HHCB \\
Tonalidea $^{\circledR}$ & $1506-02-1$ & AHTN & \\
Traseolidea $^{\circledR}$ & $68140-48-7$ & ATII
\end{tabular}

\section{MUSKETA POLIZIKLIKOEN ANALISIA}

\subsection{Arloko egoera}

Kosmetikoetan musketak analizatzeko metodoak ezinbestez garatu behar dira kosmetikoak erabiltzen dituzten kontsumitzaileen segurtasuna bermatzeko, eta kosmetikoek araudia betetzen dutela ziurtatzeko. Dena den, zientzia-literaturan ikerketa gutxi daude eskuragarri kosmetikoen analisiari dagokionez [11] —ez da gauza bera gertatzen, aldiz, ingurugiroko laginen kasuan [10]-.

Bibliografian aurki daitezkeen ikerketa gehienek gas-kromatografia erabiltzen dute musketen bereizketarako eta masa-espektrometria, berriz, detekziorako $[12,13]$. Aipatzekoa da Roosens eta bere lankideen ikerketa; izan ere, zainketa pertsonalerako produktuetan MX, MK, HHCB eta AHTN kuantifikatzeko gai izan ziren. Lan horretan 82 produktu kosmetiko aztertu zituzten - horietako 19 perfumeak - , eta kosmetikoen erabilpenaren eta neurtutako nitromusketa kontzentrazioen arteko loturak bilatu zituzten. Bestalde, elektroforesi kapilarra (CE) delako teknika indarra hartzen ari da lurrinen analisiaren esparruan [14], eta geroz eta erabiliagoa da kosmetikoen osagai desberdinen aldi bereko analisia egiteko $[15,16]$; izan ere, teknika hau oso egokia da konposatu hidrofoboen eta hidrofiloen aldibereko bereizketa elektroforetikoa lortzeko. 


\subsection{Ikerketaren helburua}

Ikerketa honek helburu modura hartu du HHCB, AHTN eta ATII musketa poliziklikoak kuantifikatzeko metodo analitikoa garatzea. Horretarako, CE teknika instrumentala erabali zen. Konposatu horiek neutroak direnez, kromatografia elektrozinetiko mizelarra (MEKC, micellar electrokinetic chromatography) deritzon aldaera erabili behar izan zen; horretaz gainera, PCMek ur-disolbagarritasun oso txikia dutenez [17], teknika ingurune ezurtsuan egin behar izan zen: NAMEKC delakoa (nonaqueous micellar electrokinetic chromatography).

\subsection{Ikerketaren muina}

Saio guztiak Agilent 7100A CE gailuan egin ziren; gailu honek diodo lerrokatuen detektagailu ultramorea (DAD) du. Laginak eta MeOH-tan prestatutako estandarrak injektatzeko 45 mbar-eko presioa egin zen 8 segundoz, eta bereizketa lortzeko $30 \mathrm{kV}$-eko potentzial-diferentzia ezarri zen. Kuantifikazioa barne patroia erabiliz egin zen, eta hain zuzen ere, 4-metil-3-penten-2-ona aukeratu zen. Detektagailuan $260 \mathrm{~nm}$-ko uhin-luzera finkatu zen AHTN, ATII eta barne patroia detektatzeko eta $280 \mathrm{~nm}$-koa, berriz, HHCBren kasuan. NAMEKC egin ahal izateko, formamida disolbatzaile organikoa erabili zen. Metodoaren garapenerako prozedura orokorra honako hau izan zen:

1. NAMEKC bidezko bereizketa analitikoan eragin adierazgarria zuten aldagaiak identifikatu ziren, esaterako, aplikatutako eremu elektrikoaren intentsitatea, bereizketa-disoluzioaren konposaketa eta $\mathrm{pHa}$.

2. Ikerketa honetan, aztertutako aldagaiak hauek izan ziren: surfaktante gisa jokatzen duen sodio dodezilsulfatoaren kontzentrazioa, 165-195 mM tartean, elektrolito modura jokatzen duen sodio dihidrogenofosfato kontzentrazioa $10-40 \mathrm{mM}$ tartean eta ezarritako potentzial-diferentzia, $20-30 \mathrm{kV}$ tartean.

3. Aldagai adierazgarriak optimizatzeko, diseinu esperimental aldagaianitza eta espresuki garatutako erantzun-funtzio kromatografikoa (MCRF) erabili ziren. Lortutako balio optimoak honako hauek izan ziren: $195 \mathrm{mM}$ sodio dodezilsulfato, $40 \mathrm{mM}$ sodio dihidrogenofosfato eta $30 \mathrm{kV}$-eko potentzial-diferentzia. 3. irudian ikus daiteke optimizazioan lortutako erantzun-gainazalaren irudikapena.

4. NAMEKC metodoan eragin adierazgarria zuten aldagaiak optimizatu ondoren, beharrezkoa zen ezaugarri analitikoak ebaluatzea: kalibrazio zuzenak, linealtasuna, detekzio eta kuantifikaziomugak, doitasuna eta zehaztasuna dira ezaugarri ohikoenak [15]. 2. taulan ikus daitezke garatutako metodoaren ezaugarri analitiko 
garrantzitsuenak. Esan behar da ezaugarri analitikoen ebaluazioa onargarria izan zela, ohikoak diren egokitasun-irizpideak oinarri hartuta [18].

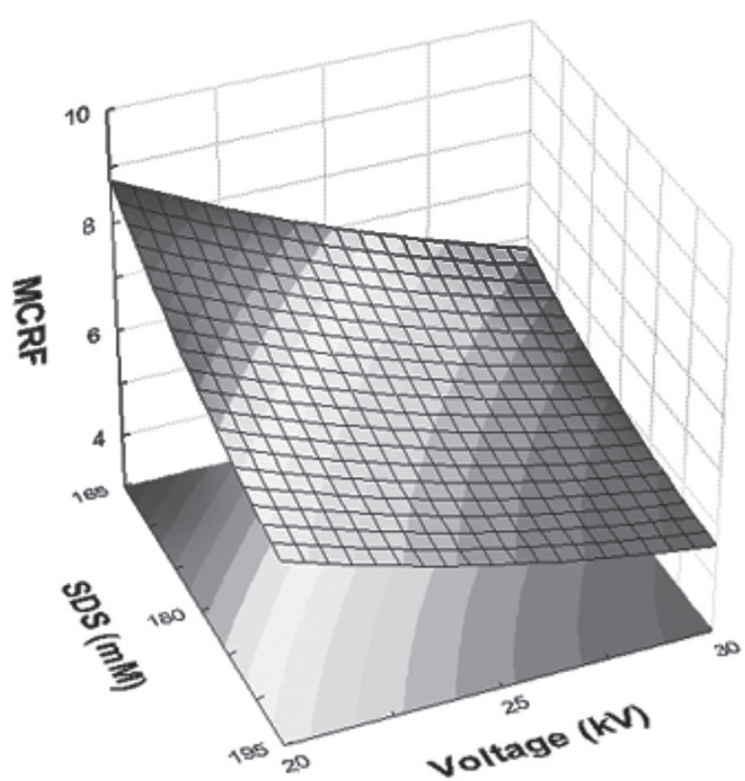

3. irudia. Eredu matematikoaren arabera MCRFri dagokion erantzun-gainazala. Irudiko gainazalean hirugarren aldagaia, alegia, elektrolito-kontzentrazioa, balio optimoan $(30 \mathrm{kV})$ finkatuta dago. Gainazalaren balio minimoak adierazten ditu baldintza optimoak.

2. taula. Metodoaren ezaugarri analitiko garrantzitsuenak.

\begin{tabular}{lcccccr}
\hline & $\begin{array}{c}\text { Tarte lineala } \\
(\mathrm{g} / \mathrm{L})\end{array}$ & $r^{\mathrm{a}}$ & $\begin{array}{c}\mathrm{LOD}^{\mathrm{b}} \\
(\mathrm{g} / \mathrm{L})\end{array}$ & $\begin{array}{c}\mathrm{LOQ}^{\mathrm{c}} \\
(\mathrm{g} / \mathrm{L})\end{array}$ & $\begin{array}{c}\text { Doitasuna }^{\mathrm{d}} \\
(\% \mathrm{RSD})\end{array}$ & $\begin{array}{c}\text { Zehaztasuna }^{\mathrm{e}} \\
(\%)\end{array}$ \\
\hline HHCB & $(50-400) \cdot 10^{-3}$ & 0,9978 & $6,5 \cdot 10^{-3}$ & $19,4 \cdot 10^{-3}$ & $0,9-6,4$ & $98,8-104,9$ \\
AHTN & $(50-400) \cdot 10^{-3}$ & 0,9976 & $3,7 \cdot 10^{-3}$ & $11,1 \cdot 10^{-3}$ & $1,0-4,3$ & $100,9-106,7$ \\
ATII & $(50-400) \cdot 10^{-3}$ & 0,9987 & $3,3 \cdot 10^{-3}$ & $9,9 \cdot 10^{-3}$ & $1,0-4,5$ & $95,7-98,0$ \\
\hline
\end{tabular}

${ }^{\mathrm{a}}$ Korrelazio koefizientea; ${ }^{\mathrm{b}}$ Detekzio muga: $\mathrm{LOD}=(3,3 \cdot \mathrm{SD}) / \mathrm{b}$; ${ }^{\mathrm{c}}$ Kuantifikazio muga:

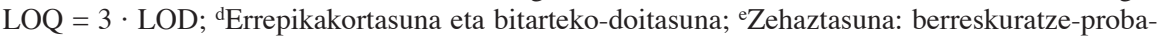
ren emaitzak. Argibide analitiko guztiak bibliografian aurki daitezke [15]. 


\subsection{Metodoaren aplikazioa}

Metodoa optimizatu eta ebaluatu ondoren, lagin errealen analisian erabili zen, hautatutako osagaien kontzentrazioa zehazteko. Laginei dagokienez, guztira Gipuzkoako hainbat dendatan lortutako 27 perfume analizatu ziren. Lagin bakoitza bi aldiz analizatu zen, batezbestekoa eta desbiderapen estandarra kalkulatu ahal izateko. Laginak prestatzeko prozedura erraza izan zen: elektroforesiko bialean bertan $400 \mu \mathrm{L}$ bereizketa-disoluzioa, $50 \mu \mathrm{L}$ barne patroia eta perfume bakoitzaren kantitate diluitu egokia jarri ziren -PCM kontzentrazioen arabera-. Azkenik, metanola gehitzen zen amaierako bolumena $600 \mu \mathrm{L}-k o a$ izan zedin eta, beharrezkoa zenean, ultrasonikazioa aplikatzen zen, lagin diluitua iragazi eta gailuan injektatu aurretik. 4. irudian ikus daiteke lagin baten kasuan detektagailuan erregistratutako elektroferograma.

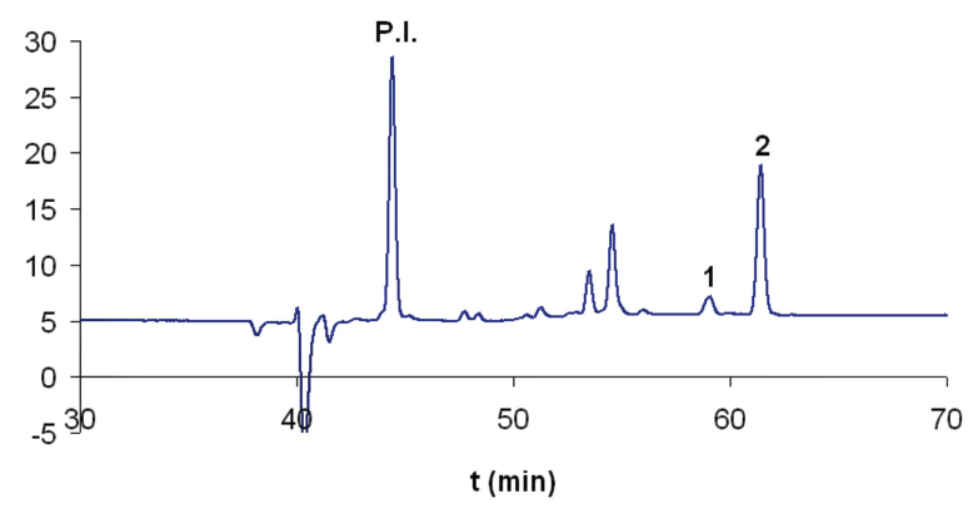

4. irudia. 27. perfumeari dagokion elektroferograma, $260 \mathrm{~nm}$-an. Seinaleen identifikazioa: P.I. $=$ Barne patroia, $1=$ HHCB, $2=$ AHTN .

27 laginen analisia egin ondoren lortutako emaitzak, g/L eta $\mathrm{g} / \mathrm{kg}$ unitateetan adierazita, 3. taulan jasota daude. HHCB 16 perfumetan aurkitu zen $(\% 59,3)$, AHTN 8 perfumetan $(\% 29,6)$ eta ATII perfume bakarrean $(\% 3,7)$. Guztira, 11 laginetan ez zen PCMrik aurkitu $(\% 40,7)$. Kontzentrazioei dagokienez, HHCB 2,6-19,3 g/kg tartean kuantifikatu zen eta AHTN, aldiz, $1,1-23,8 \mathrm{~g} / \mathrm{kg}$ tartean. Esan bezala, ATII perfume bakarrak zuen eta bere kontzentrazioa 15,6 g/kg-koa zen. 
3. taula. HHCB, AHTN eta ATII kontzentrazioak laginetan (emaitzak: batezbestekoa \pm desbiderapen estandarra).

\begin{tabular}{ccccccc}
\hline \multirow{2}{*}{ Perfumea } & \multicolumn{2}{c}{ HHCB } & \multicolumn{2}{c}{ AHTN } & \multicolumn{2}{c}{ ATII } \\
\cline { 2 - 7 } & $\mathrm{g} / \mathrm{L}$ & $\mathrm{g} / \mathrm{kg}$ & $\mathrm{g} / \mathrm{L}$ & $\mathrm{g} / \mathrm{kg}$ & $\mathrm{g} / \mathrm{L}$ & $\mathrm{g} / \mathrm{kg}$ \\
\hline 2 & $3,78 \pm 0,04$ & $4,84 \pm 0,05$ & $4,4 \pm 0,1$ & $5,6 \pm 0,2$ & - & - \\
3 & $2,0 \pm 0,1$ & $2,6 \pm 0,1$ & - & - & - & - \\
4 & $4,4 \pm 0,1$ & $5,3 \pm 0,1$ & $3,87 \pm 0,03$ & $4,71 \pm 0,04$ & - & - \\
5 & $2,4 \pm 0,1$ & $3,4 \pm 0,2$ & - & - & $12,2 \pm 0,2$ & $15,6 \pm 0,2$ \\
6 & $2,39 \pm 0,06$ & $2,93 \pm 0,08$ & $3,5 \pm 0,2$ & $4,2 \pm 0,2$ & - & - \\
9 & $7,5 \pm 0,2$ & $9,4 \pm 0,2$ & - & - & - & - \\
10 & $14,9 \pm 0,3$ & $19,3 \pm 0,4$ & $1,13 \pm 0,01$ & $1,47 \pm 0,02$ & - & - \\
13 & $2,84 \pm 0,04$ & $3,49 \pm 0,05$ & - & - & - & - \\
14 & $7,29 \pm 0,01$ & $9,04 \pm 0,01$ & $4,06 \pm 0,05$ & $5,04 \pm 0,06$ & - & - \\
17 & $3,27 \pm 0,02$ & $4,30 \pm 0,03$ & - & - & - & - \\
20 & $3,28 \pm 0,04$ & $4,25 \pm 0,05$ & - & - & - & - \\
21 & $8,78 \pm 0,03$ & $10,68 \pm 0,03$ & $19,6 \pm 0,70$ & $23,8 \pm 0,80$ & - & - \\
22 & $10,2 \pm 0,2$ & $12,2 \pm 0,2$ & - & - & - & - \\
23 & $6,6 \pm 0,3$ & $8,3 \pm 0,4$ & - & - & - & - \\
25 & $3,78 \pm 0,01$ & $4,59 \pm 0,01$ & $0,82 \pm 0,01$ & $1,08 \pm 0,01$ & - & - \\
27 & $2,92 \pm 0,02$ & $3,78 \pm 0,03$ & $1,87 \pm 0,02$ & $2,42 \pm 0,02$ & - & - \\
\hline
\end{tabular}

\section{ONDORIOAK}

Artikulu honetan laburtu den doktore-tesiaren atalean, NAMEKC metodo bakuna, fidagarria eta merkea garatu da perfumeetan HHCB, AHTN eta ATII musketa poliziklikoak aldi berean kuantifikatzeko. Metodoak ezaugarri analitiko onargarriak ditu, balioztapen prozesuko ebaluaketak adierazi duen moduan. Guztira 27 perfume analizatu dira eta guztiek araudia betetzen dutela egiaztatu da [20].

Hauxe da lehen ikerketa, elektroforesi ezurtsuari esker PCMak determinatzea ahalbidetzen duena. Horretaz gainera, laginaren prestaketa erraza proposatu da - laginaren diluzioa, besterik ez-. Bestalde, elektroforesi kapilarraren aplikazioak zabaldu dira; izan ere, konposatu oso hidrofoboak elektroforesi kapilarra erabiliz analizatzeko bidea aztertu da. Ondorioz, elektroforesian oinarritutako metodo hau gas- edo likido-kromatografian oinarritutakoen aukera egokia da, bai aplikazio kualitatiboetan eta baita kuantitatiboetan ere. 


\section{ESKER ONAK}

Lan hau Kosmetikoen osagai hautatuak determinatzeko kromatografia elektrozinetiko mizelarrean oinarritutako metodoen garapena eta aplikazioa doktore-tesiaren atal batzuetan oinarrituta dago. Tesia EHUko Kimika Aplikatua Saileko analitikako taldean gauzatu da, Esmeralda Millán EHUko irakaslearen zuzendaritzapean.

Eusko Jaurlaritzaren Hezkuntza, Hizkuntza Politika eta Kultura Sailari doktore-tesia aurrera eraman ahal izateko emandako diru-laguntza eskertzen diot. Era berean eskertzen dut EHUk Doktorego ondoko prestakuntzaprogrametan sartu arte doktore berriak kontratatzeko deialdiaren bidez emandako diru-laguntza.

\section{BIBLIOGRAFIA}

[1] LOPEZ-GAZPIO, J. eta MILLÁN, E. 2013. «Usaimena, zentzumen ahaztu hori». Ekaia, 26, 31-45.

[2] ROWE, D.J. 2005. «Introduction». In ROWE, D.J. Chemistry and technology of flavors and fragrances, Blackwell Publishing Ltd., Oxford.

[3] AL-HASSANI, S.T.S. eta WOODCOCK, E. 2006. 1001 inventions: muslim heritage in our world, Foundation for Science, Technology and Civilisation, Manchester.

[4] PYBUS, D.H. 2006. «The history of aroma chemistry and perfume». In SELL, C.S. The chemistry of fragrances, The Royal Society of Chemistry, Cambride.

[5] BAUR, A. 1891. «Studien über den künstlichen moschus». Berichte der Deutschen Chemischen Gesellschaft, 24, 2832-2843.

[6] CHISVERT, A., LÓPEZ-NOGUEROLES, M. eta SALVADOR, A. 2013. «Essential oils: analytical methods to control the quality of perfumes». In RAMAWAT, K.G. eta MÉRILLON, J.M. Natural products, Springer-Verlag, Berlin.

[7] ASIMAKOPOULOS, A.G., PASIAS, I.N., KANNAN, K. eta THOMAIDIS, N.S. 2014. «Human exposure to chemicals in personal care products and health implications». In DÍAZ-CRUZ, M.S. eta BARCELÓ, D. Personal care products in the aquatic environment, Springer International Publishing, Switzerland.

[8] LUCKENBACH, T., CORSI, I. eta EPEL, D. 2004. «Fatal attraction: synthetic musk fragrances compromise multixenobiotic defense systems in mussels». Marine Environmetal Research, 58, 215-219.

[9] TANWAR, S., DI CARRO, M., IANNI, C. eta MAGI, E. 2014. «Occurrence of PCPs in natural waters from Europe». In DÍAZ-CRUZ, M.S. eta BARCELÓ, D. Personal care products in the aquatic environment, Springer International Publishing, Switzerland. 
Perfumeen kimika: musketak eta musketa poliziklikoen analisia

[10] KRAFT, P. 2005. «Aroma chemicals IV: musks». In ROWE, D.J. Chemistry and technology of flavors and fragrances, Blackwell Publishing Ltd., Oxford.

[11] LLOMPART, M., CELEIRO, M., LAMAS, J.P., SANCHEZ-PRADO, L. eta LORES, M. 2013. «Analysis of plasticizers and synthetic musks in cosmetic and personal care products by matrix solid-phase dispersion gas chromatography-mass spectrometry». Journal of Chromatography A, 1293, 1019.

[12] ROOSENS, L., COVACI, A. eta NEELS, H. 2007. «Concentrations of synthetic musks compounds in personal care and sanitation products and human exposure profiles through dermal application». Chemosphere, 69, 15401547.

[13] HOMEM, V., SILVA, J.A., CUNHA, C., ALVES, A. eta SANTOS, L. 2013. «New analytical method for determination of musks in personal care products by Quick, Easy, Cheap, Effective, Rugged and Safe extraction followed by GC-MS». Journal of Separation Science, 36, 2176-2184.

[14] LOPEZ-GAZPIO, J. eta MILLÁN, E. 2013. Elektroforesi kapilarraren oinarriak, EHUko Argitalpen Zerbitzua, Leioa.

[15] LOPEZ-GAZPIO, J., OSTRA, M., GARCIA-ARRONA, R. eta MILLÁN, E. 2012. «Optimization and validation of a nonaqueous micellar electrokinetic chromatography method for determination of polycyclic musks in perfumes». Journal of Separation Science, 35, 1344-1350.

[16] LOPEZ-GAZPIO, J., GARCIA-ARRONA, R. eta MILLÁN, E. 2015. «Simultaneous determination of multiclass preservatives including isothiazolinones and benzophenone-type UV-filters in household and personal care products by micellar electrokinetic chromatography». Electrophoresis, 36, 1064-1072.

[17] RICKING, M., SCHWARZBAUER, J., HELLOU, J., SVENSON, A. eta ZITKO, V. 2003. «Polycyclic aromatic musk compounds in sewage treatment plant effluents of Canada and Sweden-first results». Marine Pollution Bulletin, 46, 410-417.

[18] TAVERNIERS, I., DE LOOSE, M. eta VAN BOCKSTAELE, E. 2004. «Trends in quality in the analytical laboratory. II. Analytical method validation and quality assurance». Trends in Analytical Chemistry, 23, 535-552.

[19] EUROPEAN PARLIAMENT AND COUNCIL. 2009. «Regulation (EC) No. 1223/2009 of the European Parliament and of the Council of 30 November 2009 on cosmetic products (recast)». Official Journal of the European Union, L342, 59-209. 